\title{
Caracterização e custos de acidentes de motocicleta com vítimas atendidas em regime de hospitalização no município de Paranavaí-PR no ano de 2007
}

I Andrey Rogério Campos Golias, 2 Rosangela Caetano,

${ }^{3}$ Cid Manso de Mello Vianna I

Resumo: O objetivo deste estudo foi caracterizar os acidentes de motocicletas ocorridos no município de Paranavaí-PR, em 2007, com enfoque nos custos decorrentes das vítimas que necessitaram de internação, na perspectiva do Sistema Único de Saúde e para o seguro obrigatório que cobre danos pessoais causados por veículos automotores de via terrestre, o DPVAT. Compôs-se de um estudo baseado em buscas e análises das bases de dados do Serviço Integrado de Atendimento ao Trauma e Emergência, do DPVAT e do Sistema de Informações sobre Internações do SUS. A população constou de 655 vítimas (440 homens e 215 mulheres), média de 29,5 anos, sendo que 598 (91,3\%) saíram lesionadas e 11 (1,7\%) morreram. A frequência da internação hospitalar foi, em média, de $27 \%$. As internaçôes pelo DPVAT corresponderam a $82 \%$ dos custos, sendo que o custo médio foi de R \$ 1.608,60 e as internaçôes do SUS, 18\%, com custo médio de $\mathrm{R} \$ 450,44$ por AIH e de $\mathrm{R} \$$ 596,37 por paciente. $\mathrm{O}$ custo médio da internação dos acidentes analisados foi de $\mathrm{R} \$ 1.321,00$, sendo que o custo é maior quanto mais grave é o acidente. Estes são indicativos claros da necessidade de adotar políticas públicas que priorizem a aplicação dos recursos financeiros e humanos na redução dos acidentes e da sua gravidade.

> Palavras-chave: acidentes de trânsito; veículos automotores; motocicletas; custos e análise de custo.

\author{
${ }_{1}^{1}$ Professor assistente da \\ Faculdade Ingá em Maringá-PR, \\ Brasil. Endereço eletrônico: \\ andreyfisio@gmail.com \\ 2 Professora adjunta no \\ IMS-UERJ, Rio de Janeiro, \\ Brasil. Endereço eletrônico: \\ caetano.r@gmail.com \\ ${ }^{3}$ Professor associado no \\ IMS-UERJ, Rio de Janeiro, \\ Brasil. Endereço eletrônico: \\ cdvianna@gmail.com
}


A mudança verificada na morbimortalidade brasileira associada à transição epidemiológica tem como uma de suas características e elemento de preocupação, os acidentes de trânsito (AT). Vivenciamos no país uma epidemia silenciosa, em que vidas são tiradas diariamente e muitos necessitam de tratamentos e podem ficar com sequelas para sempre. Dentre as causas externas, lesões e óbitos relacionados ao trânsito ocupam o segundo lugar em mortalidade, só superado pelos homicídios (REICHENHEIM et al., 2011), e permanecem como importante desafio aos serviços de saúde pela sua magnitude e transcendência.

Os AT constituem um problema social, não apenas por seus impactos nas taxas de mortalidade, mas também por ocasionarem custos sociais e econômicos relevantes decorrentes de consequências não mensuradas, como desestruturação de núcleos familiares e de aspectos emocionais como sofrimento e dor, como pelos custos de cuidados em saúde associados aos acidentes e a interrupção temporária ou permanente de atividades produtivas dos vitimados (IPEA; DENATRAN, 2006).

Diversas iniciativas têm sido realizadas buscando reduzir o número e impacto de AT no país nos últimos anos. Em 2001, foi definida a Política Nacional de Redução da Morbimortalidade por Acidentes e Violências, através da Portaria MS/GM no 737, de 16 de maio, que pretendeu orientar a atuação do setor saúde no contexto desses eventos, aí incluídos os ATs (BRASIL, 2001). Novas legislações (a exemplo da "Lei Seca"), controle municipal do trânsito, melhoria da segurança dos veículos e fiscalização eletrônica não conseguiram, contudo, diminuir significativamente as mortes e incapacidades decorrentes desse problema de saúde pública. Apenas em 2010, 42.830 mortes decorrentes de acidentes de transporte terrestre foram registradas no Sistema de Informações de Mortalidade, sendo a maior parte entre homens (81,6\%) nas faixas etárias de 20 a 39 anos e de 40 a 59 anos.

Do universo dos acidentes advindos do trânsito, a motocicleta vem crescendo em importância (OLIVEIRA; SOUSA, 2004; FERREIRA, 2006; IPEA; ANTP, 2004). Segundo Reichenheim et al. (2011), a proporção dos óbitos por AT envolvendo esse meio de transporte elevou-se de 4,1\%, em 1996, para 28,4\% em 2007, correspondendo a uma taxa específica de morte de 4,2/100.000 habitantes nesse ano. Das mortes relacionadas a AT em 2010, motociclistas representaram $25,4 \%$ das vítimas, seguidos por ocupantes de outros veículos (24,1\%) (BRASIL, 
2012). Esta relevância tem, como fatores subjacentes, o crescimento de sua frota,

maior do que dos outros tipos de veículo; seu menor custo, tanto de aquisição quanto de manutenção; a possibilidade de permitir deslocamentos mais rápidos, nas cidades cada vez mais caóticas, além de vir sendo frequentemente utilizado como instrumento de trabalho, no caso dos motociclistas profissionais (SILVA; SOARES; ANDRADE, 2008; GRISCI; SCALCO; JANOVIK, 2007; DINIZ; ASSUNÇÃO; LIMA, 2005).

Pelas próprias características do veículo, a vulnerabilidade do usuário da moto é evidente, já que não há proteções de lataria ou outra estrutura, e os motociclistas, em sua maioria jovens e em idade produtiva, estão constantemente propensos e sujeitos a sofrerem lesóes que podem provocar a morte ou comprometer, de forma temporária ou definitiva, sua qualidade de vida e o desenvolvimento de suas atividades, com comprometimento no retorno à sua produtividade. Além disso, a morbidade decorrente desses eventos pode levar a gastos adicionais relacionados a seu atendimento e tratamento, tanto para o sistema de saúde, quanto para seguros e para o próprio indivíduo. Internações, cirurgias, reabilitação, cuidados de assistência domiciliar e produtividade perdida pela falta de condições para realização das atividades laborais podem ser listados como elementos que geram gasto. Assim, torna-se importante conhecer esses montantes, já que parte destes recursos poderá ser reduzida se estratégias aplicadas para minimizar esse importante problema de saúde forem efetivas.

Neste sentido, esta pesquisa pretendeu caracterizar os acidentes de motocicleta ocorridos do município de Paranavaí-PR, em 2007, com enfoque nos custos decorrentes das vítimas que necessitaram de internação, na perspectiva do Sistema Único de Saúde (SUS) e para o DPVAT, seguro obrigatório cobrado anualmente dos proprietários de veículos que cobre danos pessoais causados por veículos automotores de via terrestre, com o intuito de agregar subsídios para geração de estratégias para minimizar os recursos consumidos com esses eventos.

\section{Metodologia}

Foi realizada pesquisa exploratória, seccional, retrospectiva, baseada em análises de bases de dados de acidentes ocorridos em Paranavaí, município do noroeste do estado do Paraná, que apresentava população estimada em 81,590 habitantes, segundo o último Censo de 2010 (IBGE, 2010). A pesquisa restringiu-se aos 
acidentes envolvendo motocicletas no perímetro urbano do referido município, que foram caracterizados segundo as seguintes variáveis: gênero, idade, tipo de acidente, condição da vítima no acidente, mês da ocorrência, gravidade, frequência de internação hospitalar e óbitos, além de se estimar os custos globais e por componentes de custo relacionados às eventos que demandaram internação.

Os custos diretos foram estimados nas perspectivas do SUS e DPVAT, tomando-se por base o método top-down approach (RICE, 1967), abordagem que avalia os custos na forma agregada por doença específica, utilizando dados estatísticos de gastos totais em saúde (dados secundários) e as taxas de utilização dos serviços de saúde por uma doença específica para determinar a estimativa de custo da doença (ARAUJO, 2010). Foram utilizadas de forma complementar três fontes de dados: (i) do Serviço Integrado de Atendimento ao Trauma e Emergência (SIATE), situado no $5^{\circ}$ Grupamento de Corpo de Bombeiros de Paranavaí; (ii) informações do DPVAT; e (iii) do Sistema de Informações sobre Internações Hospitalares do SUS (SIH-SUS).

Informações destas últimas duas fontes foram obtidas diretamente junto ao Hospital Santa Casa de Paranavaí, que permite o acesso direto a estas bases de dado e corresponde à única unidade hospitalar do município que realiza internações pelo SUS e pelo DPVAT, em Paranavaí.

O SIATE, em atuação desde os anos 1990, responde pelo atendimento préhospitalar às vítimas de acidentes ocorridos em vias e logradouros públicos, ou em ambientes profissionais e domiciliares. Seu atendimento é voltado exclusivamente ao trauma e inclui não apenas o cuidado aos ATs, mas também a ferimentos por arma de fogo ou arma branca, queimaduras, soterramentos, acidentes de trabalho; ou ainda problemas clínicos com risco iminente de vida. Apenas os ATs envolvendo motocicletas foram captados para o atual estudo.

A base de dados deste sistema é parcialmente aberta à população, com os dados colhidos no sítio eletrônico da Corporação de Bombeiros do Paraná (SIATE, 2008), o qual permite que sejam realizadas buscas de variáveis diversas sobre os AT no estado, inclusive aqueles de menor gravidade e que não geram internações ou óbitos. Possui um banco de dados informatizado, alimentado diariamente por profissionais especializados da Corporação dos Bombeiros, que realizam a abordagem dos acidentes e os primeiros socorros às vítimas e colhem informaçôes 
dos acidentes ocorridos. Permite buscas e geração de relatórios específicos da atuação desses profissionais, tanto em relação aos ATs quanto ao atendimento préhospitalar, com delimitação do número de vítimas, tipo de acidente e gravidade dos acidentados ao primeiro atendimento. Destaca-se, contudo, que as informações específicas sobre as vítimas, tais como seu nome, não estão disponíveis no site e foram obtidas após autorização, por escrito, do responsável pelo serviço.

O Seguro DPVAT (Danos Pessoais Causados por Veículos Automotores de Via Terrestre ou por sua Carga a Pessoas Transportadas ou Não) foi criado em 1974 e oferece cobertura à totalidade da população do país, inclusive a visitantes estrangeiros vítimas de acidentes de trânsito dentro do território nacional. Este seguro oferece três coberturas, a saber: morte, invalidez permanente ou parcial, e despesas com assistência médica e suplementares (DAMS), inclusive hospitalares. O valor da indenização é de $\mathrm{R} \$ 13.500$ nos casos de morte; de até $\mathrm{R} \$ 13.500$ nos casos de invalidez permanente e de até $\mathrm{R} \$ 2.700$ para reembolso de despesas médicas e hospitalares comprovadas (DPVAT, 2008).

De posse dos nomes das vítimas envolvidas nos acidentes com motocicletas no município em tela no ano de 2007 , foi realizada busca no sistema interno do DPVAT, que é composto por uma tabela mensal contendo o nome dos internados, com os custos respectivos de suas internaçōes, discriminados segundo um conjunto de componentes de custo, referentes a serviços hospitalares, profissionais, materiais/medicamentos e prestação de serviços.

Os nomes dos pacientes identificados no SIATE foram posteriormente utilizados para a busca no SIH-SUS, que contém dados das internações hospitalares pelo SUS. O SIH-SUS engloba aproximadamente 75 a 80\% da assistência médicohospitalar prestada à população brasileira. Foram identificadas as internações correspondentes e impressas as Autorizações de Internação Hospitalar (AIH), permitindo identificar os valores pagos e também os componentes de custo dessas internações referentes a serviços hospitalar, profissional, serviço auxiliar diagnóstico-terapêutico (SADT), órteses e próteses, sangue, internações em unidade de terapia intensiva (UTI) e despesas com acompanhantes.

A estratégia de busca utilizada consistiu em procurar pelos nomes das vítimas dos acidentes com motocicleta captados do SIATE, tanto no sistema do DPVAT quanto no SIH-SUS, no mês do acidente até quatro meses subsequentes, pois 
1128 o pagamento da internação só é gerado quando ocorre a alta do paciente e em alguns casos está se estende por período de tempo mais prolongado. Nos dois últimos sistemas, trabalhou-se com o período de janeiro de 2007 a abril de 2008. Esta estratégia também permitiu descartar as internações dos mesmos pacientes que possam ter ocorrido por outros motivos, que não aqueles relacionados ao acidente de motocicleta.

A abordagem dos dados ocorreu de acordo com a sequência dos acidentes de trânsito em Paranavaí, a seguir descrita, que se encontra resumida para melhor visualização no quadro 1:

- $1^{\circ}$ momento: O socorro ao acidente é realizado pelo SIATE. Depois dos primeiros socorros, as vítimas são classificadas neste primeiro atendimento, segundo o código de gravidade do SIATE. O socorrista do SIATE pode julgar a vítima como ilesa, quando esta aparenta não ter sofrido lesão ou consequência física do acidente, não sendo ela neste caso encaminhada a nenhuma instituição de saúde, mas há registro do ocorrido, o que permitiu sua localização nas outras duas bases de dados examinadas. Os que sofreram acidentes de pequena expressão clínica (código 1) são levados até o Pronto-Atendimento Municipal e, ocasionalmente, depois deslocados ao Hospital Santa Casa, se existir suspeita ou comprovação de lesões de maior gravidade. Aqueles com repercussões maiores (códigos 2 e 3) são levados diretamente ao Hospital Santa Casa de Paranavaí. Neste estudo, estimou-se o custo das internações tomando-se como referência este hospital. Os óbitos (código 4) são levados diretamente ao Instituto Médico Legal do município. O código 4 refere-se aos óbitos antes e durante o atendimento do SIATE. Aqueles que morrem após admissão hospitalar não são contabilizadas como código 4, mas caracterizados como outros códigos (1, 2 ou 3), quando do atendimento prestado pelo serviço de atendimento pré-hospitalar em questão.

- $2^{\circ}$ momento: Os pacientes que chegam até o hospital citados e são internados deveriam gerar AIH e custo para o SUS, mas uma parte dessas internações gera custos somente para o DPVAT. Cobertura relacionada à assistência médica (DAMS), inclusive hospitalar, indeniza até o valor máximo de $\mathrm{R} \$ 2.700,00$ (DPVAT, 2008). As despesas são transmitidas para um sistema de uso restrito que abrange o total de custo, para posterior custeio até o referido valor. 
- $3^{\circ}$ momento: É constituído apenas se necessário, caso o valor de custo de internação coberto pelo DPVAT seja ultrapassado, e o SUS torne-se o responsável pela cobertura subsequente, isto é, seja responsável pelo pagamento ao hospital.

A compreensão do fluxo dos atendimentos e internações permitiu analisar todas as internações (pelo SUS e pelo DPVAT) referentes àquelas vítimas registradas como envolvidas em acidentes de motocicleta pelo SIATE. Com base nesses dados, estimaram-se mais precisamente os custos para o SUS e para o DPVAT, assim como os custos para cada um dos códigos de gravidade do SIATE.

O estudo seguiu o disposto na Resolução n. 196/1996 do Conselho Nacional de Saúde, e foi aprovado pelo Comitê de Ética em Pesquisa da Faculdade Ingá, de Maringá-PR, sob o número 0006.0.362.259-09.

Quadro 1. Código de gravidade do SIATE, correlações clínicas e o local de encaminhamento em Paranavaí-PR, 2007

\begin{tabular}{|c|c|c|c|c|}
\hline $\begin{array}{l}\text { Código de } \\
\text { gravidade }\end{array}$ & $\begin{array}{l}\text { Correlação } \\
\text { Clínica }\end{array}$ & Exemplos & Internação & $\begin{array}{c}\text { Encaminhamento em } \\
\text { Paranavaí }\end{array}$ \\
\hline Código 1 & Ferimentos leves & $\begin{array}{l}\text { Escoriações, traumas } \\
\text { leves, sem suspeita } \\
\text { de fratura ou lesões } \\
\text { teciduais profundas }\end{array}$ & Sim/Não & $\begin{array}{l}\text { Pronto-Atendimento } \\
\text { Municipal ou Hospital } \\
\text { Santa Casa de Paranavaí }\end{array}$ \\
\hline Código 2 & $\begin{array}{c}\text { Ferimentos } \\
\text { graves sem risco } \\
\text { imediato de vida }\end{array}$ & $\begin{array}{l}\text { Lesões importantes } \\
\text { de pele, fraturas de } \\
\text { membros }\end{array}$ & Sim/Não & $\begin{array}{c}\text { Pronto Atendimento do } \\
\text { Hospital Santa Casa de } \\
\text { Paranavaí }\end{array}$ \\
\hline Código 3 & $\begin{array}{l}\text { Ferimentos } \\
\text { graves com risco } \\
\text { imediato de vida }\end{array}$ & $\begin{array}{l}\text { Polifraturas e outros } \\
\text { tipos de lesões graves em } \\
\text { membros, suspeita de } \\
\text { traumatismo abdominais } \\
\text { ou torácicos, suspeita } \\
\text { de concussões, lesões } \\
\text { cerebrais e/ou medulares }\end{array}$ & Sim & $\begin{array}{c}\text { Pronto-Atendimento do } \\
\text { Hospital Santa Casa de } \\
\text { Paranavaí }\end{array}$ \\
\hline Código 4 & $\begin{array}{l}\text { Óbitos antes } \\
\text { ou durante } \\
\text { atendimento }\end{array}$ & - & Não & Instituto Médico Legal \\
\hline
\end{tabular}




\section{Resultados e discussão}

\section{Caracterização dos acidentes e das vítimas}

No ano de 2007, ocorreram 750 acidentes de trânsito no município de ParanavaíPR, com 983 vítimas, independentemente do tipo ou consequência do acidente. Já os acidentes de motocicleta foram 504 (62,7\% dos AT), com 655 vítimas, o que significa que a cada três acidentes, dois tiveram motocicletas envolvidas. $\mathrm{O}$ mesmo acontece com o número de vítimas, pois a cada três vítimas de AT no município, duas são vitimadas em acidentes com motocicleta.

A elevada frequência de acidentes envolvendo motocicletas tem sido relatada também em outros estudos de AT no Brasil (KOIZUMI, 1985; REICHENHEIM et al., 2011; MARÍN-LEÓN et al., 2012), contribuindo para isto fatores relacionados à instabilidade própria do veículo, facilitando derrapagens em curvas, maior exposição corpórea de seus ocupantes, dificuldades de visualização da motocicleta e prevalência de comportamentos inadequados dos motociclistas no trânsito urbano (ANDRADE; JORGE, 2000). Além disso, a inexistência de medidas viárias, como faixas segregadas e exclusivas para motocicletas, e a ausência de incorporação de tecnologias para diminuir o impacto das colisões sobre os ocupantes, também favorecem acidentes com esse tipo de veículo. Especificamente no Paraná, trabalho publicado em 2013 (GOLIAS; CAETANO, 2013) identificou que acidentes com motocicleta representaram 54,2\% dos 56.729 ATs no Paraná atendidos pelo SIATE entre julho de 2010 e junho de 2011, mas com proporção bastante variável entre os municípios paranaenses.

Um aspecto importante da realidade brasileira é o expressivo crescimento da frota de motocicletas, com aumento de $61 \%$ no licenciamento desse meio de transporte entre 2002 e 2006 (VASCONCELLOS, 2008). A relação entre o número de veículos e o número de motocicletas de Paranavaí, em dezembro de 2007, era de três para um (36.014 veículos a motor e 11.276 motocicletas e motonetas) (DETRAN-PR, 2008). Isto sugere que os acidentes envolvendo motocicletas representaram uma parcela significativa frente aos demais AT.

Do total de vítimas em acidentes com motos, 598 (91,3\%) apresentavam algum tipo de lesões, não tendo sido julgadas como ilesas nem como óbito (código 4) pelo socorrista do SIATE, enquadrando-se, portanto, nos códigos de gravidade 1, 2 ou 3 (tabela 1). Já o número de vítimas fatais totalizou 11 (1,7\% dos acidentes), das quais sete $(63,6 \%)$ ocorreram antes e durante o atendimento do SIATE e apenas quatro após admissão hospitalar. 


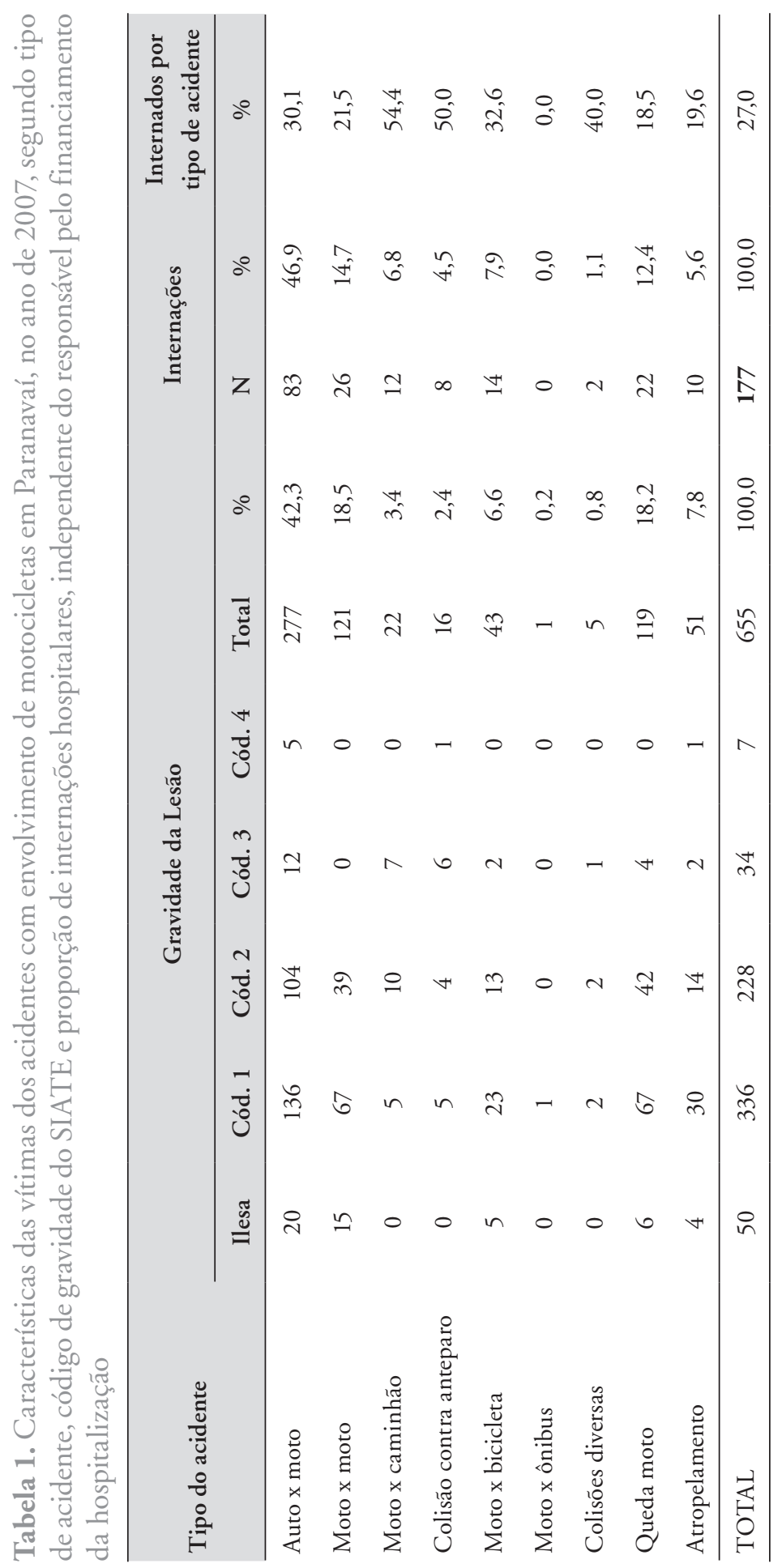


Nos Estados Unidos, a National Highway Traffic Safety Administration (NHTSA) relata que, por milha ou quilômetro de rodagem, os motociclistas são 34 vezes mais propensos a morrer do que os ocupantes de carros e oito vezes mais propensos a serem lesionados (NHTSA, 2008). E estudo realizado em Maringá, município paranaense localizado a $70 \mathrm{~km}$ de Paranavaí, em 2004, com objetivo descrever as características dos acidentes e vítimas, encontrou um percentual de $82,9 \%$ de feridos e $1,4 \%$ de óbitos (OLIVEIRA, 2008). Outro estudo realizado na mesma cidade em 1995 apontou 3,2\% de óbitos em referência aos acidentes de motocicleta (SOARES; SOARES, 2003). No ano de 1989, no município de São Paulo, a proporção de óbitos de acidentados antes da internação foi mais alta, em comparação àquelas após admissão (KOIZUMI, 1992). Este fato condiz com o presente trabalho, que verificou maior número de óbitos antes da internação.

A maior vulnerabilidade física dos condutores/ocupantes de motocicleta, que possuem o corpo mais desprotegido em relação aos motoristas de outros veículos automotores, com maiores chances de sofrer lesões em múltiplas regiōes do corpo, muitas vezes mais graves que a de outras vítimas de outros tipos de acidentes de transporte, respondem pelo elevado percentual de vitimas com lesões e possibilidade de evolução ao óbito.

As fontes de dados analisadas na pesquisa não permitem conhecer sobre um importante fator relacionado às lesōes em acidentes envolvendo motocicletas, qual seja, o uso de instrumento específico de proteção que é o capacete, embora vigore no Brasil lei de uso obrigatório desse dispositivo. Nos Estados Unidos, em 1989, no Estado de Washington, 2,1\% de todos os acidentes com motocicletas foram fatais. Os óbitos foram muito mais comuns naqueles que não usavam capacete e nos homens (ROWLAND et al., 1996). No mesmo país, estudo compreendendo 33 estados, alguns com lei universal de uso de capacete e outros não, comparando-os a hospitalizações provenientes dos acidentes de motocicleta, encontrou percentual de óbito de 1,8\% nos locais onde existia lei universal e 2,5\% onde não existia (COBEN; STEINER; MILLER, 2007). No Brasil, Liberatti e colaboradores (2003) realizaram levantamento durante um ano, no atendimento pré-hospitalar em Londrina-PR, e encontraram que $63 \%$ dos acidentados faziam uso do capacete e que a presença de hálito etílico e faixa etária inferior a 18 anos foram os principais fatores da não utilização do capacete. 
Os tipos de acidente de motocicleta que levaram a maior número de vítimas foram os que ocorreram entre automóvel e motos (42,3\%), seguidos das ocorrências entre duas motocicletas e das quedas de motocicleta (tabela 1). A análise da gravidade, segundo tipo de acidente, sugere que a maior parte desses eventos (51,3\%) provocou ferimentos leves (código 1). Alguns tipos de acidente tiveram mais vítimas julgadas como código 2 e 3 do que código 1 (entre motocicleta e caminhão e colisão contra anteparo), apontando que tais acidentes, quando acontecem, são usualmente mais graves.

Outros estudos também identificaram como ocorrência mais frequente os acidentes entre automóvel e motocicleta. Trabalho já citado de Maringá também encontrou auto x moto como o tipo de acidente mais frequente, seguido da queda de motocicleta e atropelamento (OLIVEIRA, 2008). $\mathrm{O}$ percentual de acidente entre duas motocicletas foi, contudo, bem menor $(4,87 \%)$ se comparado ao presente estudo (12,5\%). Em Londrina, estudo concluiu que o acidente mais relatado por motoboys foi a colisão com outro tipo de veículo (SILVA; SOARES; ANDRADE, 2008) Já no Rio Grande do Norte, nos últimos três meses de 2007, o acidente mais frequente foi a queda de motocicleta, seguida do auto x moto e entre duas motocicletas (BARROS, 2008). A elevada frequência de acidentes do tipo auto x moto pode se dever ao fato de que esses tipos de veículos são os mais comuns nas vias urbanas, além de o automóvel apresentar maior extensão em lataria do que a moto, e acabam disputando espaço no trânsito cada vez mais caótico das cidades.

Com relação ao gênero das vítimas, o homem foi mais acometido por este tipo de ocorrência em uma proporção de 2x1 (tabela 2). O predomínio do sexo masculino é confirmado por outros autores (OLIVEIRA, 2008; SOARES; SOARES, 2003; KOIZUMI, 1985; BARROS, 2008; OLIVEIRA; SOUSA, 2004; SANTOS et al., 2008; OLIVEIRA; SOUSA, 2006; COBEN; STEINER; MILLER, 2007; HAYAKAWA; FICHBECK; FISCHHOFF, 2000; HOANG et al., 2008; LI et al., 2008; BRANDT et al., 2002). Os homens não apenas são mais frequentes como motociclistas, como tendem a ser motoristas mais agressivos do que as mulheres, executando manobras mais arriscadas, com maior tendência de direção em situação prévia de consumo de álcool (DUARTE, 2000; FIGUEIREDO et al., 2005). 

em Paranavaí-PR, no ano de 2007, segundo gênero e faixa etária

\begin{tabular}{ccccc}
\hline Faixa etária & \multicolumn{2}{c}{ Homens } & \multicolumn{3}{c}{ Mulheres } \\
& N & $\%$ & N & $\%$ \\
\hline $\mathbf{4}$ & 3 & 0,7 & 1 & 0,5 \\
$\mathbf{5 - 9}$ & 5 & 1,1 & 3 & 1,4 \\
$\mathbf{1 0 - 1 4}$ & 6 & 1,4 & 11 & 5,1 \\
$\mathbf{1 5 - 1 9}$ & 67 & 15,2 & 40 & 18,6 \\
$\mathbf{2 0 - 2 9}$ & 199 & 45,2 & 80 & 37,2 \\
$\mathbf{3 0 - 3 9}$ & 74 & 16,8 & 40 & 18,6 \\
$\mathbf{4 0 - 4 9}$ & 43 & 9,8 & 21 & 9,8 \\
$\mathbf{5 0 - 5 9}$ & 22 & 5,0 & 7 & 3,3 \\
$\mathbf{6 0 - 6 9}$ & 12 & 2,7 & 8 & 3,7 \\
$\mathbf{7 0 +}$ & 9 & 2,0 & 4 & 1,9 \\
\hline Total & 440 & 100,0 & 215 & 100,0 \\
\hline
\end{tabular}

A análise das vítimas por faixa etária revela que jovens de 20 a 29 anos constituem o grupo mais acometido, seguidos de 30 a 39 e de 15 a 19 anos (tabela 2). A mediana de idade dos acidentados foi de 25 anos e a média de 29,5 anos, sem diferença significativa entre os sexos (média de idade entre os homens de 29,8 e entre mulheres de 28,9 anos). Vários estudos nacionais e internacionais confirmam a predominância de vítimas jovens nesses tipos de acidentes (OLIVEIRA, 2008; SOARES; SOARES, 2003; SILVA; SOARES; ANDRADE, 2008; BARROS, 2008; OLIVEIRA; SOUSA, 2004; SANTOS et al., 2008; OLIVEIRA; SOUSA, 2006; HOANG et al., 2008; ICHIKAWA; CHADBUNCHACHAI; MARUI, 2003; LI et al., 2008; YANNIS; GOLIAS; PAPADIMITRIOU, 2005; SERVADEI et al., 2003). Inexperiência, falta de familiaridade com as leis do trânsito e de habilidade no dirigir, dificuldade em perceber o perigo e resolver os problemas, maior tendência em dirigir com excessiva velocidade e de ingestão de álcool e/ou drogas antes da condução respondem pela elevada frequência de vítimas jovens neste tipo de acidente (MULLIN et al., 2000; SOARES; SOARES, 2003; ELLIOT; BAUGHAN; SEXTON, 2007; CAIXETA et al., 2010). 


\section{Análise das internaçôes relacionadas às motocicletas}

Nesta análise, não se examinaram dados das internações realizadas pela Saúde Suplementar e particulares. No mês de dezembro de 2007, 11.277 pessoas eram beneficiárias de convênios em Paranavaí (ANS, 2008), o que correspondia a pouco mais de 14\% do número de habitantes. Além disso, é bastante provável que o primeiro atendimento tenha sido realizado nas unidades de emergência municipal, para onde usualmente são levados os casos que necessitam de maior cuidado após a avaliação inicial pelo socorrista do SIATE. Desse modo, acreditase que importante parcela das internações ocorreu pelo SUS e DPVAT e estaria contemplada no quantitativo examinado.

A frequência da internação hospitalar (pelo SUS, DPVAT ou ambos) referente aos acidentados de motocicletas, em Paranavaí, no ano de 2007, foi em média $27 \%$. Esta frequência tem oscilado entre $20 \%$ e $41,4 \%$ na literatura. Estudo realizado em Maringá, que analisou todos os AT em 2000 e todas as internações, não somente aquelas referentes ao SUS ou DPVAT, identificou uma média de 19,4\% para todos os acidentes e de 41,3\% de internações para os motociclistas. Revelou ainda maior risco de internaçôes de pedestres envolvidos em acidente com motocicleta e depois de motociclistas (SOARES; BARROS, 2006). Outro estudo realizado no mesmo município, em 1995, encontrou média de internação de motociclistas de 41,4\% (SOARES; SOARES, 2003).

Alguns tipos de acidentes levaram, proporcionalmente, a mais internações, como a colisão entre motocicleta e caminhão e a colisão de motocicletas contra anteparo (tabela 1), sugerindo que estes tipos de acidentes provocam lesões mais graves que necessitam de tratamento em uma unidade hospitalar. Do total de vítimas internadas (177), 106 tiveram cobertura apenas do DPVAT, 58 apenas do SUS e 13 pacientes por ambos. Atropelamento e queda de motocicleta tiveram as maiores frequências de internação pelo SUS e as vítimas do tipo colisão entre duas motocicletas pelo DPVAT (tabela 3).

Em se tratando especificamente das vítimas de AT com motos internadas pelo SUS, a pesquisa abordou os dados dos acidentes em questão realizando buscas nominais e não através dos códigos da $10^{\text {a }}$ Revisão da Classificação Internacional de Doenças (CID-10). Foram encontradas 94 AIHs em 2007, correspondendo a 71 pacientes. Deste total, 61 tiveram somente uma internação e dez tiveram mais de uma internação no mesmo período, motivadas pela necessidade de novos 
procedimentos, como cirurgias e curativos. Verificou-se, ainda, que das $94 \mathrm{AIHs}$ registradas, várias foram preenchidas com códigos da CID-10 errados, que não correspondiam a acidentes de trânsito, Apenas cinco AIH foram preenchidas com códigos referentes a acidentes de trânsito, 42 AIHs foram codificadas como quedas e $44 \mathrm{AIHs}$ não possuíam qualquer código principal. Este fato pode levar a uma minimização do impacto dos acidentes com motocicleta, tanto em termos de sua frequência quanto em seus custos. Documento do Ministério da Saúde também se refere à presença de problemas de preenchimento e sub-registro de eventos relacionados a causas externas e violências (BRASIL, 2005), que precisam ser considerados na realização de estudos utilizando a base de dados do SIH-SUS.

Tabela 3. Número de vítimas dos acidentes com envolvimento de motocicletas segundo o tipo de acidente, internadas pelo DPVAT, pelo SUS e por ambos, em Paranavaí-PR, no ano de 2007

\begin{tabular}{lccccccc}
\hline \multirow{2}{*}{ Tipo de acidente } & \multicolumn{2}{c}{ DPVAT } & \multicolumn{2}{c}{ SUS } & \multicolumn{2}{c}{ Ambos } & \multirow{2}{*}{$\begin{array}{c}\text { Total de } \\
\text { internados }\end{array}$} \\
\cline { 2 - 6 } & $\mathrm{N}$ & $\%$ & $\mathrm{~N}$ & $\%$ & $\mathrm{~N}$ & $\%$ & 83 \\
\hline Auto x moto & 55 & 66,3 & 20 & 24,1 & 8 & 9,6 & 26 \\
Moto x moto & 19 & 73,1 & 4 & 15,4 & 3 & 11,5 & 12 \\
Moto x caminhão & 7 & 58,3 & 4 & 33,3 & 1 & 8,3 & 8 \\
Colisão em anteparo & 5 & 62,5 & 3 & 37,5 & 0 & 0,0 & 14 \\
Moto x bicicleta & 9 & 64,3 & 5 & 35,7 & 0 & 0,0 & 0 \\
Moto x ônibus & 0 & 0,0 & 0 & 0,0 & 0 & 0,0 & 2 \\
Colisões diversas & 1 & 50,0 & 1 & 50,0 & 0 & 0,0 & 22 \\
Queda moto & 8 & 36,4 & 14 & 63,6 & 0 & 0,0 & 10 \\
Atropelamento & 2 & 20,0 & 7 & 70,0 & 1 & 10,0 & 177 \\
\hline TOTAL & $\mathbf{1 0 6}$ & 59,9 & $\mathbf{5 8}$ & 32,8 & $\mathbf{1 3}$ & 7,3 & \\
\hline
\end{tabular}

\section{Custos das internações para o DPVAT e SUS}

As internaçōes por acidentes relacionados a motocicletas em Paranavaí, em 2007, geraram custo total de R \$ 191.423,43 para o DPVAT e um custo médio de R \$ $1.608,60$ por internação, em 2007. No SUS, esses acidentes geraram o pagamento 
de $\mathrm{R} \$ 42.342,20$, perfazendo a média de $\mathrm{R} \$ 450,44$ por $\mathrm{AIH}$ e de $\mathrm{R} \$ 596,37$ por paciente. Este resultado diferiu do valor médio por AIH encontrada no DATASUS para o mesmo município e período, que foi de $\mathrm{R} \$ 629,84$ (BRASIL, 2008). Isto decorreu da diferença entre os 19 pacientes internados após acidente de motocicleta dispostos na base do DATASUS, e as $94 \mathrm{AIH}$ encontradas pelo presente estudo, o que confirma o impacto econômico do sub-registro já relatado.

O custo médio da internação do SUS por acidentes de transporte em São José dos Campos (primeiro semestre, 2003) foi de R \$ 614,63 (MELIONE; JORGE, 2008). Para o estado de São Paulo, este custo, em 2000, foi de R $\$ 721,15$ (JORGE; KOIZUMI, 2004). Não é possível, contudo, fazer comparações diretas entre os valores aqui estimados e estes: não apenas eles se referem a acidentes de transporte de um modo geral e não apenas a AT envolvendo motocicletas, como se relacionam a períodos e populações diferentes. Podendo ter havido atualizações dos valores nas tabelas de pagamento de procedimentos ou decorrerem de perfis não necessariamente semelhantes dos acidentados e tipos de lesões.

O principal componente de custo para o DPVAT foi o serviço hospitalar (39\%), seguido dos materiais e medicamentos (35\%) e serviços profissionais (22\%). Os componentes que geraram maior custo para o SUS foram serviço hospitalar (52\%), seguido do serviço profissional (22\%), órteses e próteses (17\%), serviço auxiliardiagnóstico-terapêutico (SADT, 3\%), sangue (3\%), UTI (2\%) e despesas com acompanhantes (1\%). Não há uma correspondência direta entre os componentes de custo presentes nas duas bases de pagamento, e parte das órteses e próteses custeadas pelo DPVAT encontra-se sob a rubrica materiais e medicamentos.

Nas internações por causas externas (novembro 1994) em todo o Brasil, os serviços hospitalares foram mais onerosos que os materiais e medicamentos e os serviços profissionais (IUNES, 1997). Um achado interessante no atual trabalho e no citado diz respeito aos elevados dispêndios relacionados à órteses e próteses, já que, provavelmente, necessitou-se mais deste serviço por causa da alta prevalência de lesões traumato-ortopédicas, como fraturas, luxações e lesões, muito comuns neste tipo de acidente (IPEA; ANTP, 2004).

O custo total das internações das vítimas de acidentes com motocicleta em Paranavaí no ano de 2007 foi de $\mathrm{R} \$ 233.765,63$. O DPVAT foi responsável pelo pagamento de $82 \%$ destes custos e o SUS, $18 \%$. Pode-se dizer que o DPVAT faz o SUS "economizar" uma parcela importante dos custos com acidentes 
1138 de motocicleta. No Brasil, poucos são os motociclistas que contratam seguros privados, devido a seu alto preço.

De acordo com Instituto de Pesquisa Econômica Aplicada (IPEA) e o Departamento Nacional de Trânsito (DENATRAN, 2006), com base em estudo realizado entre os anos de 2003 e 2006, os ATs representam custos anuais da ordem de R $\$ 28$ bilhōes no Brasil. Custos com AT no Brasil foram estimados em $\mathrm{R}$ \$ 3,6 bilhôes (abril de 2003) de acordo com a pesquisa "Impactos sociais e econômicos dos ATs nas aglomerações urbanas", realizada pelo IPEA. Esses custos foram determinados com base no tratamento e reabilitação das vítimas, na recuperação ou reposição dos bens materiais danificados, no custo administrativo dos serviços públicos envolvidos e nas perdas econômicas e previdenciárias (IPEA; DENATRAN, 2006). De acordo com a mesma pesquisa, em 2005, as motocicletas representavam $14 \%$ da frota nacional de veículos e respondiam por $25 \%$ dos gastos com acidentes, totalizando $\mathrm{R} \$ 5,3$ bilhões. Os custos hospitalares com acidentes de motocicletas atingiam valor médio de $\mathrm{R} \$ 47.888,00$ para os casos graves com internação e os custos com reabilitação chegam a torno de $\mathrm{R} \$$ $56.000,00$. Todos esses números apenas reforçam o elevado ônus que os ATs e, neles, o ATs envolvendo motocicletas, representam para a economia do país, reforçando a necessidade de investimento e aprimoramento contínuo para sua redução, que envolvem desde a regulamentação do trânsito, intervenções da engenharia de tráfego e transportes e ações educativas, dentre outras.

Segundo estudo realizado em rodovias brasileiras, a internação correspondeu a mais de 32\% dos custos associados à pessoa (IPEA; DENATRAN, 2006). Isto significa que, possivelmente, o impacto das internaçôes abordadas pela atual pesquisa tem importante significado dentro dos custos totais.

Tomando-se por base a análise do custo total das internações para o SUS e para o DPVAT, chegou-se à estimativa de custo médio para os referidos órgãos, segundo os códigos de gravidade do SIATE (tabela 4). Como esperado, o custo médio aumenta conforme a gravidade da lesão. Os resultados referentes a uma vítima julgada como código 4 e uma como ilesa não puderam ser levados em consideração e não estão presentes na tabela 4 , já que foi registrado somente um caso cada, além de que foram julgados erroneamente pelo SIATE, pois geraram internação. 
Tabela 4. Custo total e médio das internaçôes $(\mathrm{R} \$)$, segundo códigos de gravidade

(SIATE) das vítimas dos acidentes com envolvimento de motocicletas, em ParanavaíPR, no ano de 2007

\begin{tabular}{cccc}
\hline Código & N $^{\circ}$ de pacientes & Custo total R\$ & Custo médio R\$ \\
\hline $\mathbf{1}$ & 53 & $46.906,76$ & 885,00 \\
$\mathbf{2}$ & 96 & $132.208,13$ & $1.377,00$ \\
$\mathbf{3}$ & 26 & $52.880,42$ & $2.034,00$ \\
\hline TOTAL & - & $\mathbf{2 3 3 . 7 6 5 , 6 3}$ & $\mathbf{1 . 3 2 1 , 0 0}$ \\
\hline
\end{tabular}

As considerações finais deste trabalho necessitam ser precedidas de algumas questōes importantes para a compreensão de suas potenciais contribuições e limitações. A dimensão dos custos é bastante ampla e apenas uma parcela destes foi aqui abordada. Analisaram-se apenas os custos médicos diretos relacionados às internaçóes hospitalares. Outros custos diretos ligados à assistência, como o atendimento pré-hospitalar e o tratamento de reabilitação, não foram considerados, como também não foram incluídos custos pessoais e familiares diretos com o tratamento e reabilitação das vítimas ou custos indiretos associados à perda de produtividade e perdas materiais decorrentes dos agravos.

O intervalo temporal de análise, restrito a um ano, e o exame de dados relativos a um único município brasileiro são outra limitação a ser mencionada. Essas restrições não permitem generalizações nem capturar tendências ou variações temporais nos acidentes, elemento importante para avaliação e ajuste das estratégias de prevenção e cuidado a essas ocorrências. Mais estudos que abordem esta temática de forma mais abrangente são fundamentais para se estimar o impacto econômico dos ATs relativos a motocicletas no país.

Embora a busca de informações tenha sido iniciada a partir do SIATE e se desconheça sua efetiva cobertura em relação às vítimas de ATs, sabe-se que o número de vítimas atendidas por esse sistema é cerca de $50 \%$ superior ao número registrado em boletins de ocorrência policial (BASTOS; ANDRADE; SOARES, 2005). Ressaltam-se, ademais, as dificuldades de obtenção de dados secundários nos sistemas de informação existentes sobre esses eventos. 


\section{Considerações finais}

O estudo abordou tema ainda pouco explorado na literatura, em particular no que se refere às estimativas de custos relacionadas aos AT envolvendo motocicletas. Confirma estudos preliminares em vários pontos, dentre os quais se destacam a maior prevalência de homens jovens; a alta taxa de feridos; os tipos de acidente mais frequentes (auto x moto); a maior ocorrência de óbitos antes da internação; e a frequência de internaçôes em acidentes deste tipo. Revela ainda outros resultados, tais como o custo das internaçōes advindas dos acidentes de motocicletas, os serviços hospitalares como o componente de custo mais oneroso, a relação entre os custos das internaçôes e a gravidade julgada pelo SIATE na hora do acidente e a importante parcela de responsabilidade do DPVAT frente aos acidentes de motocicleta e frente ao SUS.

A metodologia utilizada reforça a presença de limitação quanto à fonte de informação do SIH-SUS, quando abordados pelos códigos de internação como elemento de uso exclusivo desta base de dados para estudos de custos dos acidentes de transporte, modo geral, e de motocicletas em particular. Por conta da busca nominada, foi possível identificar internações e custos associados que de outra forma não seriam contabilizados. Além disso, a relevância do DPVAT no financiamento de parcela dos custos relativos às internaçôes por pacientes envolvendo motocicletas é outro elemento importante a ser considerado em estimativas dessa natureza. Reitera-se, assim, a importância de melhorias na codificação das AIHs e a utilização de bases complementares de informações para estudos de custos envolvendo esses eventos.

Estratégias devem ser efetivadas no sentido de propor ações direcionadas à população mais afetada pelos acidentes em questão. A complexidade do problema, para sua prevenção e controle, implica aplicação de medidas no âmbito de políticas sociais, elaboração de legislação específica e desenvolvimento de instrumentos de intervenção voltados a prevenção, tratamento e reabilitação dos atingidos, o que pressupõe identificar grupos e fatores de risco.

Estimativas dos custos com internações advindas dos acidentes com motocicletas apenas reforçam a necessidade de se formular e aplicar estratégias que promovam a redução dos ATs no país. Este é um indicativo claro da necessidade de adotar políticas públicas que priorizem a aplicação dos recursos financeiros e humanos, com vistas à redução dos acidentes e da sua gravidade. 
A mídia valoriza a repercussão do acidente e pouco destaca as ações realizadas no sentido da melhoria do trânsito. Acredita-se que seja fundamental a correta alocação de recursos no sentido de melhorar a formação do condutor, de instituir campanhas nacionais direcionadas aos motociclistas, melhorias na malha viária, aumento no rigor e no número das fiscalizações, além de aprimoramento no atendimento aos acidentados. ${ }^{1}$

\section{Referências}

AGÊNCIA NACIONAL DE SAÚDE SUPLEMENTAR. Informaçôes sobre beneficiários dos convênios. Disponível em: <http://www.ans.gov.br/anstabnet/tabcgi.exe?anstabnet/ dados/TABNET_02.DEF>. Acesso em: 08 fev 2009.

ANDRADE, S.M.; JORGE, M.H.P.M. Características das vítimas por acidentes de transporte terrestre em município da Região Sul do Brasil. Rev Saúde Pública, v. 34, p. 149-56, 2000.

ARAUJO, D.V. Temas importantes na Saúde. Custo de Gerenciamento de doenças. Guia de Economia e Gestão em Saúde. São Paulo: Manole, 2010.

BARROS, W.C.T.S. Avaliação da gravidade do trauma em condutores de motocicletas vítimas de acidente de trânsito no RN. 2008. Dissertação (Mestrado em Enfermagem) - Universidade Federal do Rio Grande do Norte, Natal, 2008.

BASTOS, Y.G.; ANDRADE, S.M.; SOARES, D.A. Características dos acidentes de trânsito e das vítimas atendidas em serviço pré-hospitalar em cidade do Sul do Brasil, 1997/2000. Cad Saúde Pública, v. 21, n. 3, p. 815-822, 2005.

BRANDT, M. et al. Hospital cost is reduced by Motorcycle helmet use. J Trauma, v. 53, n. 3, p. 469-471, 2002.

BRASIL. Ministério da Saúde. Departamento de Informação e Informática do SUS. Sistemas de Informaçôes sobre Internações Hospitalares (SUS). 2008. Disponível em: <http:// tabnet.datasus.gov.br/cgi/deftohtm.exe?idb2007/d13.def>. Acesso em: 27 set. 2008.

. Ministério da Saúde. Política Nacional de redução da morbimortalidade por acidentes e violências. Portaria n. 737, de 16 mai 2001. Disponível em: < http://portal.saude.gov.br/ portal/arquivos/pdf/portaria737.pdf>. Acesso em: 13 mai 2013. 28p.

Ministério da Saúde. Secretaria de Vigilância em Saúde. Departamento de Análise de Situação de Saúde. Saúde Brasil 2011: uma análise da situação de saúde e a vigilância da saúde da mulher. Brasília: Ministério da Saúde, 2012.

- Ministério da Saúde. Secretaria de Vigilância em Saúde. Impacto da violência na saúde dos brasileiros. Textos Básicos de Saúde, 2005. Disponível em: <http://www.prosaude. org/publicacoes/diversos/impacto_violencia.pdf>. Acesso em: 08 fev. 2009. 
CAIXETA, C.R. et al. Morbidade por acidentes de transporte entre jovens de Goiânia, Goiás. Ciênc. saúde coletiva, v. 15, n. 4, p. 2075-2084, 2010.

COBEN, J.H.; STEINER, C.A.; MILLER, T.R. Characteristics of motorcycle-related hospitalizations: Comparing states with different helmet laws. Accid Anal Prev, v.39, n. 1, p. 190-196, 2007.

DANOS PESSOAIS CAUSADOS POR VEÍCULOS AUTOMOTORES DE VIA TERRESTRE. Site oficial do seguro obrigatório. Disponível em: <http://www.dpvatseguro. com.br>. Acesso em: 27 set. 2008.

DEPARTAMENTO DE TRÂNSITO DO PARANÁ. Frota de veículos cadastrados no estado do Paraná : posição em dezembro de 2007. Disponível em: <http://www.detran. pr.gov.br/arquivos/File/estatisticasdetransito/frotadeveiculoscadastradospr/2007/ frotaveiculostipomunicipiodezembro2007.pdf>. Acesso em: 09 nov. 2008.

DINIZ, E.P.H.; ASSUNÇÃO, A.A.; LIMA, F.P.A. Prevenção de acidentes: o reconhecimento das estratégias operatórias dos motociclistas profissionais como base para a negociação de acordo coletivo. Ciênc. saúde coletiva, v. 10, n.4, p. 905-916, 2005.

DUARTE, D. O comportamento no trânsito. Trânsito - Revista da Associação Brasileira dos Departamentos de Trânsito-ABDETRAN. v. 3, n. 7, p. 30-33, 2000.

ELLIOT, M.A.; BAUGHAN, C.J.; SEXTON, B.F. Errors and violations in relation to motorcyclists' crash risk. Accid Anal Prev, v.39, n. 3, p.:491-499, 2007.

FERREIRA, C.C. Acidentes motocicleta-carro: um estudo das representações sociais no trânsito de Goiânia. Dissertação (Mestrado em Psicologia) - Universidade Católica de Goiás, Goiânia, 2006.

FIGUEIREDO, L.M.B. et al. Comportamentos no trânsito e ocorrência de acidentes motociclísticos entre funcionários de um hospital universitário. Espaç Saúde, v. 7, p. 46$52,2005$.

GOLIAS, A.R.C.; CAETANO, R. Acidentes entre motocicletas: análise dos casos ocorridos no estado do Paraná entre julho de 2010 e junho de 2011. Ciênc. saúde coletiva, v. 18, n. 5 , p. 1235-1246, 2013.

GRISCI C.L.I.; SCALCO P.D.; JANOVIK M.S. Modos de trabalhar e de ser de motoboys: a vivência espaçotemporal contemporânea. Psicol Cienc Prof., v. 27, n. 3, p. 446-461, 2007.

HAYAKAWA, H.; FICHBECK, P.S.; FISCHHOFF, B. Traffic accident statistics and risk perception in Japan and the United States. Accid Anal Prev, v. 32, p. 827-835, 2000.

HOANG, H.T.M. et al. The cost of traumatic brain injury due to motorcycle accidents in Hanoi, Vietnam. Cost Eff Resour Alloc., v. 6, n. 17, 2008.

ICHIKAWA, M.; CHADBUNCHACHAI, W.; MARUI, E. Effect of the helmet act for motorcyclists in Thailand. Accid Anal Prev., v. 35, p. 183-189, 2003. 
INSTITUTO BRASILEIRO DE GEOGRAFIA E ESTATÍSTICA. Censo 2010. Primeiros

dados do Censo 2010. Dados: Paraná. Disponível em: <http://www.censo2010.ibge.gov.br/ primeiros_dados_divulgados/index.php?uf=41>. Acesso em 16 ago. 2013.

INSTITUTO DE PESQUISA ECONÔMICA APLICADA; ASSOCIAÇÃO NACIONAL DE TRANSPORTES PÚBLICOS. Impactos sociais e econômicos dos acidentes de trânsito em aglomeraçôes urbanas. Brasília, 2004. Disponível em: <http://www.ipea.gov.br/sites/000/2/ estudospesq/acidentesdetransito/Renavam.pdf>. Acesso em: 27 set. 2008.

INSTITUTO DE PESQUISA ECONÔMICA APLICADA; DEPARTAMENTO NACIONAL DE TRÂNSITO. Impactos sociais e econômicos dos acidentes de trânsito nas rodovias brasileiras. Relatório Executivo. Brasília, 2006. Disponível em: <http://www.ipea. gov.br/005/00502001.jsp?ttCD_CHAVE=276>. Acesso em: 27 set. 2008.

IUNES, R.F. Impacto econômico das causas externas no Brasil: Um esforço de mensuração. Rev Saúde Pública, v. 31, n. 4, p. 38-46, 1997.

JORGE M.H.P.M.; KOIZUMI M.S. Gastos governamentais do SUS com internações hospitalares por causas externas: Análise no estado de São Paulo, 2000. Rev Bras Epidemiol., v. 7, n. 2, p. 228-238, 2004.

KOIZUMI, M.S. Acidentes de motocicleta no município de São Paulo, SP, Brasil. 1. Caracterização do acidente e da vítima. Rev Saúde Pública, v. 19, n. 5, p. 475-489, 1985.

KOIZUMI, M.S. Padrão das lesões das vítimas de acidente de motocicleta. Rev Saúde Pública, v. 26, n. 5, p. 306-315, 1992.

LI, L. et al. Improper motorcycle helmet use in provincial areas of a developing country. Accid Anal Prev, v. 40, p. 1937-1942, 2008.

LIBERATTI, C.L.B. et al. Uso do capacete por vitimas de acidentes de trânsito de motocicleta em Londrina, sul do Brasil. Rev.Panam Salud Publica, v. 13, n. 1, p. 33-38, 2003.

MARÍN-LEÓN, L. et al. Tendência dos acidentes de trânsito em Campinas, São Paulo, Brasil: importância crescente dos motociclistas. Cad Saúde Pública. Rio de Janeiro, v. 28, n. 1, p. 39-51, 2012.

MELIONE, L.P.R.; JORGE, M.H.P.M. Gastos do SUS com internações por causas externas em São José dos Campos, SP, Brasil. Cad Saúde Pública. Rio de Janeiro, v. 24, n. 8, p. 1814-1824, 2008.

MULLIN, B. et al. Increasing age and experience: are both protective against motorcycle injury? A case-control study. Inj Prev., v. 6, n. 1, p. 32-35, 2000.

NATIONAL HIGHWAY TRAFFIC SAFETY ADMINISTRATION. Traffic Safety Facts 2005. Washington, DC, Disponível em: <http://www-nrd.nhtsa.dot.gov/Pubs/810631. PDF>. Acesso em: 28 set. 2008. 
OLIVEIRA, N.L.B. Fatores associados ao risco de lesões e óbito de motociclistas envolvidos em ocorrências de trânsito. Tese (Doutorado em Enfermagem) - Escola de Enfermagem, Universidade de São Paulo, São Paulo, 2008.

OLIVEIRA N.L.B.; SOUSA, R.M.C. Motociclistas frente às demais vítimas de acidentes de trânsito no município de Maringá. Acta Sci Health Sci, v. 26, n. 2, p. 303-310, 2004.

OLIVEIRA N.L.B.; SOUSA, R.M.C. Retorno à atividade produtiva de motociclistas vítimas de acidentes de trânsito. Acta Paul Enf., v. 19, n. 3, p. 284-289, 2006.

REICHENNHEIM, M.E. et al. Violência e lesões no Brasil: efeitos, avanços alcançados e desafios futuros. The Lancet, v. 6736, n. 11, p. 75-89, 2011.

RICE, D.P. Estimating the cost of illness. Am J Public Health, v. 57, n. 3, p. 424-440, 1967.

ROWLAND, J. et al. Motorcycle helmet use and injury outcome and hospitalizations costs from crashes in Washington State. Am J Public Health, v. 86, n. 1, p. 41-45, 1996.

SANTOS, A.M.R. et al. Perfil das vítimas de trauma por acidente de moto atendidas em um serviço público de emergência. Cad Saúde Pública, v. 24, n. 8, p. 1927-1938, 2008.

SERVADEI, F. et al. Effect of Italy's motorcycle helmet law on traumatic brain injury. Inj Prev, v. 9, p. 257-260, 2003.

SERVIÇO INTEGRADO DE ATENDIMENTO AO TRAUMA E EMERGÊNCIA. Dados estatísticos. $4^{\circ}$ Grupamento de Bombeiros, Cascavel - PR. Disponível em: <http:// www.bombeiroscascavel.com.br/>. Acesso em 27 set. 2008.

SILVA, D.W.; SOARES D.A.; ANDRADE S.M. Atuação profissional de motoboys e fatores associados à ocorrência de acidentes de trânsito em Londrina-PR. Epidemiol Serv Saúde, v. 17, n. 2, p. 123-153, 2008.

SOARES, D.F.P.P.; BARROS, M.B.A. Fatores associados ao risco de internação por acidentes de trânsito no município de Maringá-PR. Rev Bras Epidemiol., v. 9, n. 2, p. 193205, 2006.

SOARES, D.F.P.P.; SOARES, D.A. Motociclistas vítimas de acidentes de trânsito em município da região Sul do Brasil. Acta Sci Health Sci., v. 25, n. 1, p. 87-94, 2003.

VASCONCELLOS, E.A. O custo social da motocicleta no Brasil. Revista dos Transportes Públicos, v. 30/31, p. 127-42, 2008.

YANNIS, G.; GOLIAS, J.; PAPADIMITRIOU, E. Driver age and vehicle engine size effects on fault and severity in young motorcyclists accidents. Accid Anal Prev, v. 37, p. 327333, 2005. 
${ }^{1}$ Baseado na dissertação de mestrado do primeiro autor, apresentada ao Programa de Pós-graduação em Saúde Coletiva do IMS-UERJ em 2009. A.R.C. Golias participou de todas as etapas do manuscrito (revisão bibliográfica, coleta e análise de dados, elaboração e revisão crítica do texto). R. Caetano contribuiu com a revisão bibliográfica, elaboração e revisão crítica do texto final. C.M.M. Vianna colaborou na elaboração e revisão crítica do texto. Os autores agradecem à Corporação dos Bombeiros e à Santa Casa, ambos de Paranavaí, pelo acesso aos bancos de dados. 


\section{Abstract}

\section{Characterization and costs of motorcycle accidents with victims treated under} hospitalization in the city of Paranavai in 2007 This study aimed to characterize motorcycle accidents in the city Paranavaí, state of Parana, Brazil, in 2007, focusing in hospital costs, in the perspective of the Brazilian National Health System (the so-called SUS) and for the compulsory insurance that covers personal damages caused by road vehicles (DPVAT). It was based on research and analyses of databases of the Trauma and Emergency Integrated Care (SIATE), of DPVAT and SUS Admissions Information System (SIH-SUS). Population consisted of 655 victims (440 men and 215 women), 29.5 years old on average, 598 (91.3\%) got injured and $11(1.7 \%)$ died. The frequency of the hospital admission was, on average, $27 \%$. The admissions by DPVAT corresponded to $82 \%$ of costs, and the medium cost was of $R \$ 1,608.60$ and SUS admissions, $18 \%$, with medium cost of $\mathrm{R} \$ 450.44$ by AIH and $\mathrm{R} \$ 596.37$ by patient. Mean cost of all admissions was $\mathrm{R} \$ 1,321.00$, and the cost is higher when the accident is more serious. These clearly indicate the need of adopting public policies that prioritize the application of financial and human resources in the reduction of accidents.

Key words: accidents; traffic; motor vehicles; motorcycles; costs and cost analysis. 